\title{
Jefferson
}

Thomas Jefferson University

$\overline{\text { HOME OF SIDNEY KIMMEL MEDICAL COLLEGE }}$

JHN Journal

Volume 13 | Issue 1

Article 4

Winter 2018

\section{Principles of Pituitary Surgery}

Christopher J Farrell, MD

Thomas Jefferson University

Gurston G. Nyquist, MD

Thomas Jefferson University

Alexander Farag, MD

Thomas Jefferson University

Marc Rosen MD

Thomas Jefferson University

James J. Evans

Thomas Jefferson University

Follow this and additional works at: https://jdc.jefferson.edu/jhnj

\section{Let us know how access to this document benefits you}

\section{Recommended Citation}

Farrell, MD, Christopher J; Nyquist, MD, Gurston G.; Farag, MD, Alexander; Rosen, Marc MD; and Evans, James J. (2018) "Principles of Pituitary Surgery," JHN Journal: Vol. 13 : Iss. 1 , Article 4.

DOI: https://doi.org/10.29046/JHNJ.013.1.004

Available at: https://jdc.jefferson.edu/jhnj/vol13/iss1/4

This Article is brought to you for free and open access by the Jefferson Digital Commons. The Jefferson Digital Commons is a service of Thomas Jefferson University's Center for Teaching and Learning (CTL). The Commons is a showcase for Jefferson books and journals, peer-reviewed scholarly publications, unique historical collections from the University archives, and teaching tools. The Jefferson Digital Commons allows researchers and interested readers anywhere in the world to learn about and keep up to date with Jefferson scholarship. This article has been accepted for inclusion in JHN Journal by an authorized administrator of the Jefferson Digital Commons. For more information, please contact: JeffersonDigitalCommons@jefferson.edu. 


\section{Principles of Pituitary Surgery}

Christopher J. Farrell, MD; Gurston G. Nyquist, MD²; Alexander A. Farag, MD²; Marc R. Rosen, MD²; James J. Evans, MD ${ }^{1}$

${ }^{1}$ Department of Neurological Surgery, Thomas Jefferson University

2 Department of Otolaryngology, Thomas Jefferson University

\section{INTRODUCTION}

\section{Evolution of Transsphenoidal Surgery}

Since the initial description of a transnasal approach for the treatment of pituitary tumors in 1907, transsphenoidal surgery has undergone a continuous evolution marked by close collaboration between neurosurgeons and otolaryngologists. Oskar Hirsch, developed a lateral endonasal approach in 1910 that he initially performed as a five step procedure over a several week period before simplifying the procedure to a singlestep submucosal transseptal approach. ${ }^{1}$ Contemporaneously, Harvey Cushing began approaching pituitary tumors using a transsphenoidal approach but transitioned to the transcranial route due to his concern that an endonasal approach provided restricted access and poor illumination, compromising adequate decompression of the optic apparatus. ${ }^{2}$ Most neurosurgeons followed Cushing's lead and transsphenoidal surgery was not "rediscovered" until Jules Hardy introduced the surgical microscope in the 1960s. ${ }^{3}$

The first completely endoscopic transsphenoidal approach for pituitary tumors was reported in 1992 by Jankowski and further advanced by the collaborative teams of Jho and Carrau in Pittsburgh and Sethi and Pillay in Singapore. ${ }^{4,5}$ Over the last 20 years, the endoscopic technique has been adopted by a multitude of surgeons who have favored the dynamic panoramic view afforded by the endoscope, allowing for improved visualization and better resection of tumors extending into the suprasellar area and cavernous sinuses. Additionally, the advent of extended endoscopic endonasal approaches, such as the trans-planum and lateral trans-cavernous, has facilitated resection of large, invasive pituitary tumors that were previously deemed unresectable or requiring transcranial surgery.

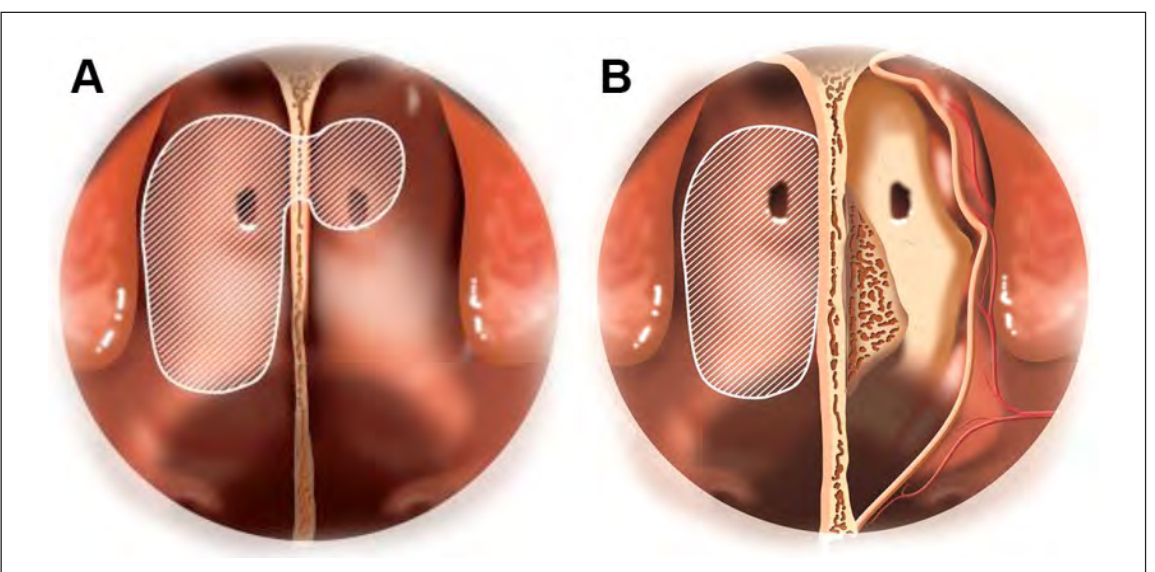

Figure 1. Nasal stage.

A. "1.5" approach to the sphenoid sinus with wide ipsilateral sphenoidotomy and limited contralateral sphenoidotomy with preservation of inferiorly located sphenopalatine arterial supply to the nasoseptal flap. B. "Tunnel" approach for patients with septal spurs with ipsilateral wide sphenoidotomy and submucosal elevation of septal mucoperichondrium
Critics of the endoscopic approach have rightfully focused on the loss of stereoscopic vision as a major limitation with mastery of the procedure demanding a steep learning curve. Prospective studies directly comparing the microscopic and endoscopic approaches for pituitary tumors have not been performed, however, an increasing body of literature has established the safety and non-inferiority of endoscopic endonasal techniques and several studies have demonstrated improvement in the extent of tumor resection. McLaughlin et al. reported that following microsurgical resection of pituitary adenomas, endoscopy revealed residual tumor leading to further resection in $36 \%$ of cases. ${ }^{6}$ Messerer et al. found their gross total resection rate increased from $50 \%$ utilizing the microscope to $76 \%$ upon initial conversion to the endoscopic approach. ${ }^{7}$ In this review, we describe the principles of pituitary surgery including the key-elements of surgical decision-making and discuss the technical nuances distinguishing the endoscopic from the microscopic approach

\section{PRINCIPLES OF SURGERY}

\section{Indications for Surgery}

Pituitary adenomas are most frequently categorized as functional or nonfunctional depending on their hormonal secretory pattern. Prolactinomas represent the most common functional adenoma and the mainstay of treatment is dopamine-agonist medical therapy, with surgical treatment reserved for patients who fail to respond despite dose-escalation or are intolerant to the medications. Transsphenoidal surgery remains the primary treatment for adenomas secreting ACTH (Cushing's disease) and growth-hormone (acromegaly) with biochemical remission rates significantly correlated with tumor size and invasiveness. ${ }^{\text {? }}$

Non-functional pituitary adenomas (NFPA) are extremely common autopsy and radiographic studies reveal the presence of NFPA in $11-27 \%$ of the 
population $(8,9)$. While most NFPA are microadenomas $(<1 \mathrm{~cm})$ and clinically asymptomatic, macroadenomas may present with compressive symptoms including headache, visual impairment, hormonal insufficiency, and cranial nerve palsies due to cavernous sinus extension. Surgery is generally indicated for patients with macroadenomas causing visual compromise or exhibiting growth on serial imaging studies. Approximately $5 \%$ of patients with pituitary adenomas present with apoplexy due to intratumoral hemorrhage or infarction. ${ }^{10}$

\section{Preoperative Surgical Planning}

The main goal in endoscopic pituitary surgery is to maximize tumor resection while avoiding complications such as visual deterioration, cerebrospinal fluid (CSF) leakage, endocrinopathy, vascular injury, and sinonasal morbidity. Although pituitary adenomas are typically benign lesions, recurrences are common following incomplete surgical removal and thorough preoperative surgical planning is essential to achieve optimal outcomes.

Magnetic resonance imaging (MRI) studies reliably delineate the size and extension of pituitary tumors, with the notable exception of some ACTHsecreting microadenomas that may be radiographically occult. Inspection of the preoperative MRI provides an assessment of the likelihood of gross total resection primarily based on cavernous sinus extension as well as a prediction of the surgical challenges that will be encountered such as intraoperative CSF leakage and a narrow surgical corridor due to reduced distance between the parasellar carotid arteries. Large tumors that extend vertically within the suprasellar area may significantly compromise the diaphragma sellae or even invade the ventricular system resulting in highflow CSF leaks requiring more extensive repairs such as nasoseptal flap (NSF) placement, lumbar drainage, or use of autologous tissues (e.g., fascia lata or adipose tissue). As discussed in more detail later, preoperative anticipation of the need for a NSF is critical as the flap must either be harvested during the initial nasal stage of the approach or the vascular pedicle to the flap preserved such that a viable flap can be harvested later should it prove necessary. Additionally, detection of the position of the normal compressed pituitary gland on the pre-operative MRI assists with the preservation of hormonal function as intraoperative distinction of the gland from tumor based on color and consistency differences is frequently subtle.

Computed tomography studies provide complementary information helpful in surgical planning. Coronal and sagittal reconstructions reveal bony changes such as erosion of the sellar floor and dorsum and can be used intraoperatively for image guidance, especially in patients with altered sinonasal anatomy related to prior surgery. Similarly, we have found preoperative nasal endoscopy helpful to optimize our surgical plan and avoid complications related to paranasal sinus disease or anatomic variability. Typically, chronic rhinosinusitis does not represent an absolute contraindication to transsphenoidal surgery, however, patients with acute rhinosinusitis, especially those with fungal disease, should be treated appropriately prior to elective surgery. ${ }^{11}$ Otolaryngology preoperative evaluation is critical in patients with acromegaly who frequently present challenges for airway management during surgery due to soft tissue hypertrophy and bony abnormalities. ${ }^{12}$

\section{Surgical Approach: Nasal Stage}

The endoscopic surgical approach for pituitary tumors can be divided into the nasal, sphenoidal, and sellar stages. Since the inception of our endoscopic skull base program at Thomas Jefferson University in 2005, we have advocated for a team approach between otolaryngology and neurosurgery. The complementary skill of experienced sinus and pituitary surgeons has enabled us to optimize oncologic outcomes and minimize complications, both minor and major. Our approach to pituitary surgery has evolved and we have adopted a tailored approach to these tumors based on their size, invasiveness, and secretory pattern allowing us to minimize sinonasal disruption without compromising tumor resection.

Patients are positioned supine with the head on a gel headrest. Neuronavigation is used routinely to help guide the surgical approach and assess the adequacy of tumor resection with co-registration of the preoperative $\mathrm{CT}$ and MR images using facemask fiducials. Although neuronavigation is valuable, over-reliance on this adjunct and a failure to correlate with anatomic landmarks can lead the surgeon off course. The head is slightly elevated to reduce mucosal congestion and venous oozing/bleeding during the approach. We do not routinely prepare the skin of the face or nasal cavity with antiseptic solution, but graft sites such as the lateral thigh for fascia lata or adipose tissue should be prepared in a sterile standard fashion.

The turbinates are gently lateralized with a blunt instrument. Although routine resection of the middle turbinates is favored by some surgeons to increase the nasal working corridor, we have found that turbinate lateralization combined with a limited posterior septectomy provides more than sufficient access to the sella for pituitary tumor resection and minimizes post-operative patient sinonasal morbidity. ${ }^{13,14} \mathrm{~A}$ binarial approach is typically performed allowing for two surgeons to work simultaneously with up to four instruments in the field, including the endoscope. In our experience, a pedicled nasoseptal flap (NSF) is rarely necessary for cranial base repair during standard transsellar pituitary adenoma resection, however, in certain cases the need for a NSF is unanticipated or may become necessary during future surgeries. ${ }^{15}$ As such, we advocate at least unilateral preservation of the NSF whenever possible and have described a variety of tailored approaches to the sphenoid sinus that enable NSF preservation applicable to endoscopic pituitary surgery. Our standard approach, termed the "1.5 approach", involves an ipsilateral wide sphenoidotomy ("1") on the working instrument side with a limited contralateral sphenoidotomy ("0.5") on the endoscope side (Figure 1A). The limited sphenoidotomy is performed by extending the natural sphenoid os superiorly with Kerrison rongeurs, thus preserving the more inferiorly located sphenopalatine artery supply to the nasal septal mucoperiosteum and mucoperichondrium. Addition of a limited posterior septectomy (typically $1 \mathrm{~cm}$ ) allows communication of the binarial sphenoid exposures and provides ample working room and maneuverability 
(unpublished data). In patients with nasal obstruction due to septal deviation or large spurs, a "tunnel approach" is performed involving a septoplasty and submucosal "tunnel" with a wide contralateral sphenoidotomy (Figure 1B). The approach begins with a standard hemitransfixion incision used for septoplasty and the septal mucoperichondrium is raised and extended posteriorly over the vomer and laterally along the sphenoid rostrum. A septoplasty or spur removal is then performed, with the resultant unilateral "tunnel" analogous to the standard microscopic transeptal approach with preservation of the NSF ipsilaterally. On the contralateral side, a wide sphenoidotomy is performed. If NSF harvest proves necessary, the superior and inferior incisions for the flap can be performed and elevation completed on the "tunnel" side. The NSF harvest and replacement ("raise and return") approach involves a standard harvest of the NSF combined with a wide contralateral sphenoidotomy. We typically reserve this approach for cases in which there is a high likelihood of NSF utilization such as tumors with very significant vertical suprasellar extension or that extend anteriorly over the planum where, depending on tumor consistency, an extended endonasal approach may become necessary for complete tumor resection. This approach is also used for cases with potential for a high-flow CSF leak. If cranial base repair with the NSF proves unnecessary, the flap can be returned to its native position along the septum. These "raised and returned" flaps tend to heal quite well with minimal crusting and post-operative discomfort. We do not advocate routine harvest of the NSF, however, as this technique is associated with increased sinonasal morbidity including the possibility of olfactory dysfunction, septal perforation, and sensory loss due to superior alveolar nerve injury. A variety of authors have described "rescue flap" modifications where the nasoseptal flap is partially raised during the nasal stage such that the vascular pedicle is preserved, although these modifications have been associated in some cases with increased risk of olfactory loss. ${ }^{16,17}$

\section{Surgical Approach: Sphenoid Stage}

The anatomy of the sphenoid sinus is highly variable in regard to its bony septa and pneumatization. The configuration of sphenoid sinus pneumatization can significantly affect access to the sella. The pneumatization of the sphenoid sinus is usually completed by age ten and the majority of adults possess the wellpneumatized sellar pattern. ${ }^{18}$ The sellar floor lies along the posterior wall of the sphenoid sinus within the midline and the importance of maintaining a midline orientation cannot be overstated. In addition to the sellar prominence, anatomic landmarks along the posterior sphenoid wall include the medial and lateral opticocarotid recesses, parasellar carotid prominences, and clival recess. Frequently, the entirety of these landmarks may not be plainly apparent and careful attention to the preoperative imaging combined with judicious use of neuronavigation will prevent inadvertent complications. The intra-sphenoidal septa should be taken down with use of the high-speed drill or Thru-cutting instruments, avoiding any fracturing or rotational maneuvers as these septa often have posterior attachments along the carotid prominences. Additionally, anticipating the presence of Onodi air cells will prevent injury to the optic nerves. Endoscopic transsphenoidal pituitary approaches can be safely performed in children and adults with the conchal and pre-sellar variant patterns, but prolonged drilling will be required along with an increased reliance on neuronavigation.

The sella is typically expanded in the presence of macroadenomas and the bony floor may be thinned or absent. Conversely, microadenomas do not cause expansion or thinning of the sellar floor, often requiring bone removal with a diamond burr to access the dura. The sphenoid mucosa should be stripped from the sellar floor bluntly or with gentle bipolar cautery prior to drilling the sella. Monopolar cautery may lead to optic nerve or carotid injury and its use is highly contraindicated along the posterior sphenoid wall. If a NSF will be placed for repair, further mucosal stripping should be performed to prevent delayed mucocele development by trapping mucosa under the flap. Bony removal of the sellar floor is usually performed with rotatable Kerrison rongeurs after a pilot bony opening has been created with the drill or Cottle elevator. As opposed to the microscopic approach where all but the central portion of the intrasellar tumor is removed based on "feel", bony removal for the endoscopic approach needs to be more extensive to maximize the visualization benefits of the endoscope and allow for tumor dissection. In the endoscopic approach, the anterior wall of the sella should be removed to the medial edges of the cavernous sinuses bilaterally and extended superiorly to the intracavernous sinus in the region of the tuberculum sella (Figure 2A). The amount of bony removal of the sellar floor is variable, however, for tumors with significant suprasellar extension additional removal of the floor allows for introduction of more vertically angled instruments helpful in removing tumor that fails to descend into the sella following debulking. For tumors that clearly invade the cavernous sinuses, further lateral bony removal across the anterior face of the parasellar carotid arteries can be performed.

\section{Surgical Approach: Sellar Stage}

The exposed dura of the sella is then opened in a cruciate fashion with a retractable knife and angled scissors. Horizontal cuts should be made in a lateral-to-medial direction to avoid carotid injury while the vertical incision should be made in a superior-to-inferior direction to avoid inadvertent entry into the anterior arachnoid cistern with resultant CSF leakage (Figure 2A). The principles of tumor removal differ for micro- and macro-adenomas. Historically, pituitary adenomas have been resected in a piecemeal fashion using a variety of blunt ring curette-type instruments. Oldfield et al., however, demonstrated the advantages of dissection of the histologic pseudocapsule surrounding pituitary adenomas, allowing microadenomas to ideally be resected in an en-bloc extracapsular fashion (Figure 2B). ${ }^{19}$ When feasible, en bloc resection reduces the likelihood of tumor remnants and increases biochemical remission for functional adenomas. ${ }^{20}$ Rarely, in patients with Cushing's disease, a pituitary microadenoma may not be visible on MR imaging but the diagnosis confirmed by adrenocorticotropic hormone (ACTH)dependent elevation of cortisol levels and 


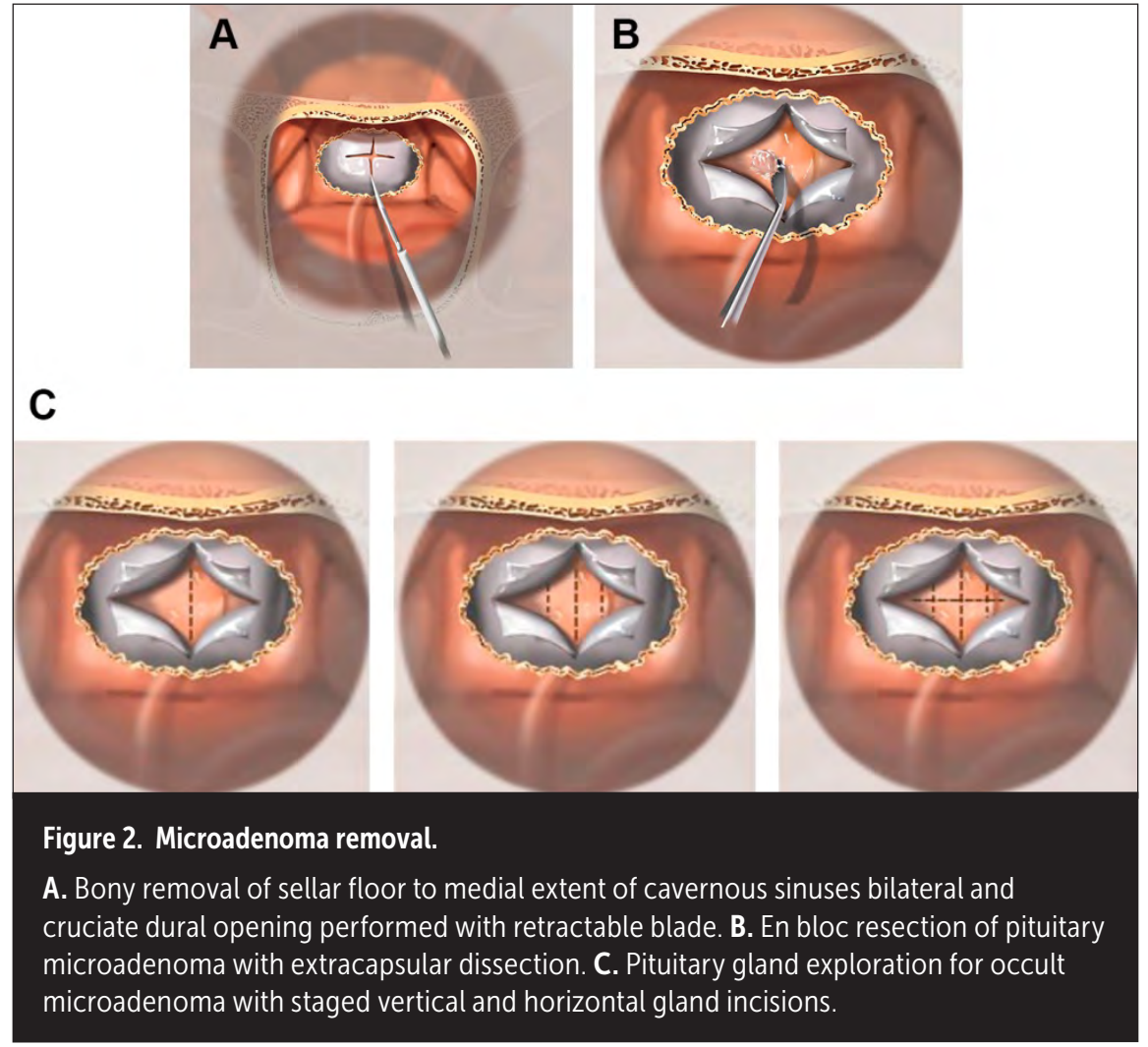

high-dose dexamethasone suppression. In these cases, ACTH levels are measured from the inferior petrosal sinuses using invasive catheters to determine the likely side of the adenoma within the sella. The pituitary gland is then explored systematically using a series of horizontal and vertical incisions to identify the adenoma beginning on the presumptive side (Figure 2C).

En bloc resection of macroadenomas is rarely possible and we advocate a strategy of systematic internal debulking followed by extracapsular dissection along the cavernous sinus walls and diaphragm. As shown in Figure 3, the inferior aspect of the tumor is first debulked with ring curettes in the midline before extending posteriorly to the dorsum sella and laterally toward the medial cavernous sinus walls. Pituitary adenomas are frequently soft tumors and overzealous interior debulking can lead to premature diaphragma sellae herniation with subsequent trapping of tumor within the folds of the collapsed arachnoid. Manipulation of the diaphragm in order to complete tumor removal from these folds often leads to compromise and intraoperative CSF leakage. To avoid this, the lateral superior recesses should be debulked prior to continued midline debulking. Once the tumor has been adequately debulked, the interface between the dura and the tumor pseudocapsule is defined with angled curettes and developed in an extracapsular fashion toward the medial cavernous sinus wall. For tumors without true cavernous sinus invasion, this pseudocapsule can be dissected circumferentially and then brought down away from the diaphragm. The transition zone between the normal gland and the tumor must be anticipated and carefully developed to avoid injury to the gland and resultant pituitary insufficiency.

Infrequently, pituitary macroadenomas may be extremely fibrous and resection of these tumors can be considerably more dangerous due to the need for sharp debulking, placing the carotid arteries and optic apparatus at increased risk for injury. We have found use of ultrasonic aspirators and side-cutting rotatable microdebriders (NICO Myriad
System, NICO corp.) extremely helpful in performing tumor debulking with location of the carotid arteries repetitively confirmed with neuronavigation and the micro-Doppler. In rare cases where adequate decompression cannot be safely performed through a standard transsphenoidal transsellar opening, we convert to an extended endoscopic approach (EEA) with drilling of the tuberculum sella and planum. The additional bony removal and more anterior dural opening enables tumor to be dissected from the optic nerves and chiasm under direct visualization but requires more extensive skull base repair.

The most frequent areas of tumor residual following transsphenoidal resection of pituitary macroadenomas are the cavernous sinuses and suprasellar area. ${ }^{21}$ Once tumor resection is felt to be completed, the sellar cavity is directly inspected with $30-70^{\circ}$ endoscopes, with careful attention to these areas as well as for detection of tumor remnants adherent to the normal pituitary gland.

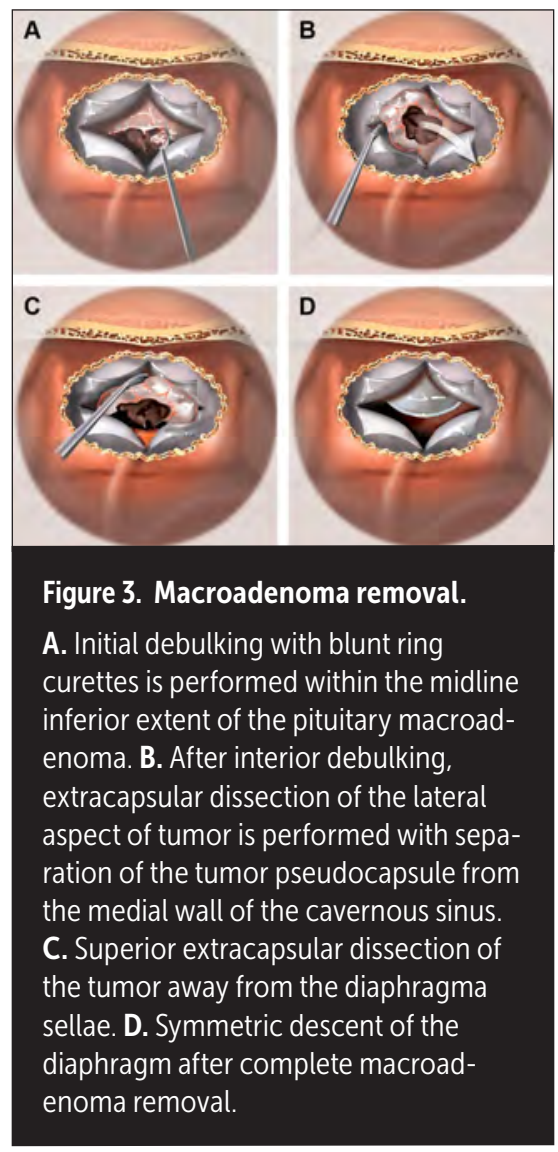



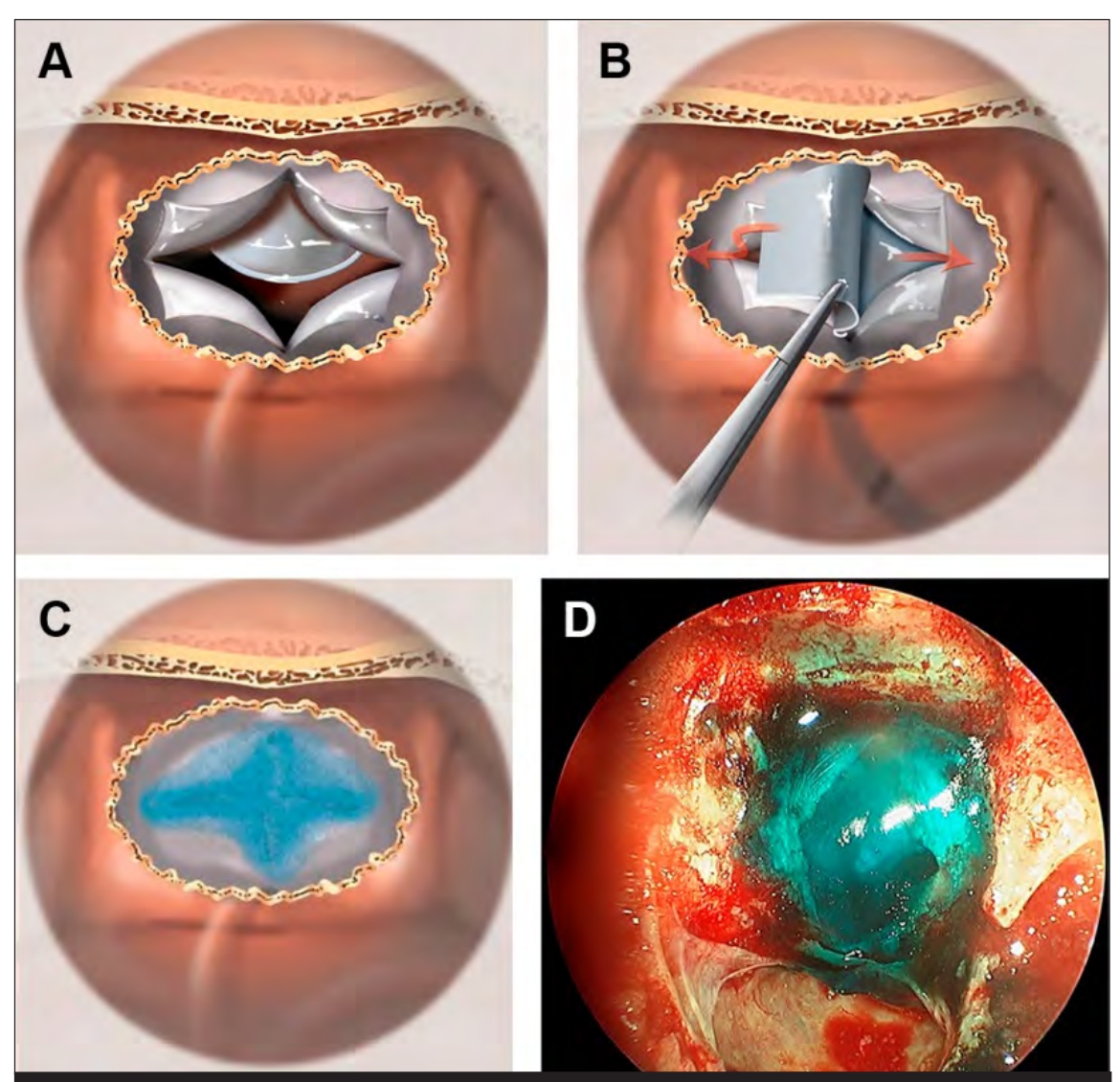

Figure 4. Dural reconstruction.

A. Intrasellar cavity after tumor resection with incompetent diaphragma sellae and

low-flow CSF leakage. B. Placement of "inlay" synthetic dural substitute beneath leaves

of dura. C. Supplementation of dural graft with tissue sealant. D. Intraoperative view after dural reconstruction with watertight closure.

Symmetric descent of the diaphragm into the sella is usually indicative of optic chiasm decompression and failure of the diaphragm to descend or asymmetric descent should prompt further search for residual tumor. After final confirmation of complete tumor resection, meticulous hemostasis is achieved with the use of hemostatic matrix agents and gentle packing with cottonoids. In our experience, the most common reason for postoperative hemorrhage has been incomplete tumor resection and absolute hemostasis is necessary when residual tumor is expected.

A graded approach to dural reconstuction is performed and in the absence of any intraoperative CSF leakage as confirmed by Valsalva maneuver, the dura is simply covered with a layer of absorbable hemostatic cellulose to promote epithelialization. Small dural defects resulting in low-flow CSF leakage are repaired with a synthetic dural substitute inlay graft placed under the leaflets of the dural opening and supplemented with a thin layer of dural sealant (Figure 4). For larger diaphragmatic defects, the arachnoid is directly repaired with an onlay dural substitute covering the site of leakage followed by placement of an inlay dural graft and sealant. For EEA and high-flow leaks related to entry into the ventricular system, a NSF is used to buttress the synthetic dural graft repair or a fascia lata "button" graft repair as previously described. ${ }^{25}$ Lumbar drain placement and nasal packing are rarely necessary for CSF leak avoidance.

\section{Cavernous Sinus Invasion}

The cavernous sinuses are paired thinwalled venous channels located lateral to the sella. The internal carotid artery (ICA) and its branches course within the center of the channel with the oculomotor, trochlear, abducens, and trigeminal cranial nerves located more laterally. Pituitary adenomas commonly invade the medial wall of the cavernous sinus within the carotid siphon with the extent of invasion predicting the likelihood of gross total tumor resection. Although the endoscopic approach provides improved visualization of tumor within the cavernous sinus, complete resection remains challenging. ${ }^{23}$ In the majority of patients, the presence of residual benign adenoma within the cavernous sinuses can be managed expectantly or with radiation therapy (e.g., stereotactic radiosurgery or stereotactic radiotherapy) with control rates for non-functional tumors typically around $90 \% .{ }^{24}$ Tumor control rates following radiosurgery are significantly reduced, however, for larger volume tumors demonstrating the importance of maximal surgical debulking prior to radiation treatment. Biochemical remission rates for functional adenomas are significantly lower than tumor control rates with remission achieved in only approximately half of patients with Cushing's disease and acromegaly. ${ }^{25}$ As such, more aggressive resection of functional tumors invading the cavernous sinus is often appropriate with the goal of either achieving complete resection or reduction of the residual tumor volume for subsequent radiosurgery.

Surgical approaches to the cavernous sinus include the medial and lateral approaches. The medial approach (Figure $5 \mathrm{~A}$ ) is a continuation of the standard transsphenoidal approach but involves following the adenoma through the cavernous sinus medial wall breach. To increase access to the cavernous sinus, the sellar bony opening is extended laterally across the anterior face of the carotid artery. Intrasellar tumor resection is completed before entry into the cavernous sinus. The cavernous sinus should be approached through the contralateral nare using angled ring curettes and suctions to optimize the angle of attack with visualization performed using a $30-70^{\circ}$ endoscope. 


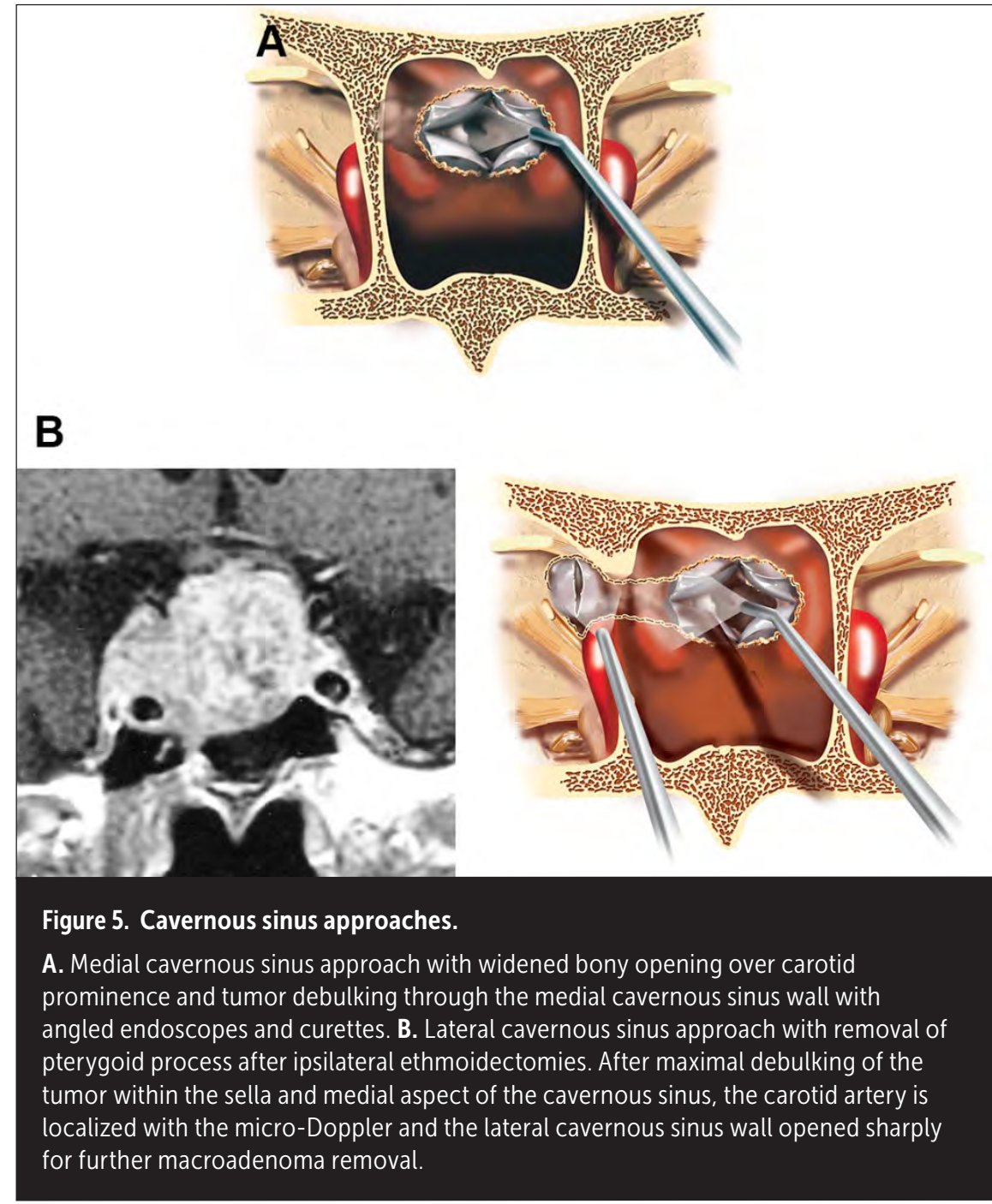

Further opening of the medial cavernous wall may be required to allow for instrument entry and is done using sharp dissection after the exact position of the carotid artery has been confirmed with Doppler ultrasonography. Vigorous venous bleeding is expected following removal of tumor from the cavernous sinus and is usually easily controlled with hemostatic matrix agents.

A lateral cavernous sinus approach may be considered in patients harboring functional adenomas or who have failed prior radiation with the bulk of their cavernous sinus tumor volume lateral to the carotid artery, although the risk of cranial nerve and ICA injury are significantly increased with this approach (Figure
$5 B)$. Fortunately, the majority of cranial nerve palsies are transient, resolving within several weeks or months, and use of electrophysiologic monitoring of the oculomotor, trochlear, and abducens nerves may further reduce the likelihood of permanent injury. To access the region lateral to the carotid artery, a wide lateral sphenoid sinus exposure is necessary often with a transpterygoid extension. During the nasal stage, a complete unilateral anterior and posterior ethmoidectomy is performed after removal of the middle turbinate. The vidian canal is identified in the lateral floor of the sphenoid sinus and the superomedial aspect of the pterygoid process is removed to expose the lateral aspect of the cavernous sinus. Careful evaluation of the preoperative $\mathrm{CT}$ images helps determine the access to the lateral cavernous sinus and in some patients with large, well-pneumatized sphenoid sinuses, access may be achieved through the lateral sphenoid sinus recess without extensive pterygoid drilling. After carotid artery localization with the microDoppler, the dura is opened sharply and tumor resected. A multi-layered closure with NSF coverage is then performed.

The most feared and potentially devastating morbidity with the cavernous sinus approaches is ICA rupture with the likelihood of injury increased with fibrous tumors and prior irradiation. Management of carotid artery injury will be more extensively discussed in other chapters of this edition but typically requires intraoperative control using direct compression followed by vessel sacrifice in the interventional angiography suite. ${ }^{26}$

\section{CONCLUSION}

Endoscopy represents the most recent evolution of transsphenoidal surgery. Although the endoscopic approach has not been proven to be superior to the classical microscopic approach for resection of pituitary adenomas, the benefits of endoscopy become most apparent during removal of large, invasive tumors where the panoramic visualization afforded by the endoscope allows for more complete resections to be performed. As neurosurgeons continue to take on the challenge of endoscopy and surmount their learning curve, endoscopic transsphenoidal surgery for pituitary adenomas will certainly become the standard.

\section{REFERENCES}

1. Lanzino G, Laws ER. Pioneers in the development of transsphenoidal surgery: Theodor Kocher, Oskar Hirsch, and Norman Dott. J Neurosurg. 2001 Dec;95(6):1097-103.

2. Liu JK, Cohen-Gadol AA, Laws ER, Cole CD, Kan P, Couldwell WT. Harvey Cushing and Oskar Hirsch: early forefathers of modern transsphenoidal surgery. J Neurosurg. 2005 Dec;103(6):1096-104. 
3. Patel SK, Husain Q, Eloy JA, Couldwell WT, Liu JK. Norman Dott, Gerard Guiot, and Jules Hardy: key players in the resurrection and preservation of transsphenoidal surgery. Neurosurg Focus. 2012 Aug;33(2):E6.

4. Jankowski R, Auque J, Simon C, Marchal JC, Hepner H, Wayoff M. Endoscopic pituitary tumor surgery. The Laryngoscope. 1992 Feb;102(2):198-202.

5. Jho HD, Carrau RL. Endoscopic endonasal transsphenoidal surgery: experience with 50 patients. J Neurosurg. 1997 Jul;87(1):44-51.

6. McLaughlin N, Eisenberg AA, Cohan $P$, Chaloner CB, Kelly DF. Value of endoscopy for maximizing tumor removal in endonasal transsphenoidal pituitary adenoma surgery. J Neurosurg. 2013 Mar;118(3):613-20.

7. Messerer M, De Battista JC, Raverot G, Kassis S, Dubourg J, Lapras V, et al. Evidence of improved surgical outcome following endoscopy for nonfunctioning pituitary adenoma removal. Neurosurg Focus. 2011 Apr;30(4):E11.

8. Naidich MJ, Russell EJ. Current approaches to imaging of the sellar region and pituitary. Endocrinol Metab Clin North Am. 1999 Mar;28(1):45-79, vi.

9. Molitch ME, Russell EJ. The pituitary "incidentaloma." Ann Intern Med. 1990 Jun 15;112(12):925-31.

10. Nawar RN, AbdelMannan D, Selman WR, Arafah BM. Pituitary tumor apoplexy: a review. J Intensive Care Med. 2008 Apr;23(2):75-90.

11. Nyquist GG, Friedel ME, Singhal S, Beahm DD, Farrell CJ, Evans JJ, et al. Surgical management of rhinosinusitis in endoscopic-endonasal skull-base surgery. Int Forum Allergy Rhinol. 2015 Apr;5(4):339-43.

12. Friedel ME, Johnston DR, Singhal $S, A l$ Khalili K, Farrell CJ, Evans JJ, et al. Airway management and perioperative concerns in acromegaly patients undergoing endoscopic transsphenoidal surgery for pituitary tumors. Otolaryngol-Head Neck Surg Off J Am Acad Otolaryngol-Head Neck Surg. 2013 Dec;149(6):840-4

13. Schmitt $H$, Buchfelder M, Radespiel-Tröger $M$, Fahlbusch R. Difficult intubation in acro megalic patients: incidence and predictability. Anesthesiology. 2000 Jul;93(1):110-4.

14. Cavallo LM, Messina A, Cappabianca P, Esposito F, de Divitiis E, Gardner P, et al. Endoscopic endonasal surgery of the midline skull base: anatomical study and clinical considerations. Neurosurg Focus. $2005 \mathrm{Jul}$ 15;19(1):E2.

15. Nyquist GG, Anand VK, Brown S, Singh A, Tabaee A, Schwartz TH. Middle turbinate preservation in endoscopic transsphenoidal surgery of the anterior skull base. Skull Base Off J North Am Skull Base Soc Al. 2010 Sep;20(5):343-7.
16. Hadad G, Bassagasteguy L, Carrau RL, Mataza JC, Kassam A, Snyderman CH, et al. A novel reconstructive technique after endoscopic expanded endonasal approaches: vascular pedicle nasoseptal flap. The Laryngoscope. 2006 Oct;116(10):1882-6.

17. Griffiths CF, Cutler AR, Duong HT, Bardo G, Karimi K, Barkhoudarian G, et al. Avoidance of postoperative epistaxis and anosmia in endonasal endoscopic skull base surgery: a technical note. Acta Neurochir (Wien). 2014 Jul;156(7):1393-401.

18. Otto BA, Bowe SN, Carrau RL, Prevedello DM Ditzel Filho LF, de Lara D. Transsphenoidal approach with nasoseptal flap pedicle transposition: modified rescue flap technique. The Laryngoscope. 2013 Dec;123(12):2976-9.

19. Hong SD, Nam D-H, Park J, Kim HY, Chung $\mathrm{S}-\mathrm{K}$, Dhong $\mathrm{H}-\mathrm{J}$. Olfactory outcomes after endoscopic pituitary surgery with nasoseptal "rescue" flaps: electrocautery versus cold knife. Am J Rhinol Allergy. 2014 Dec;28(6):517-9.

20. Hamid O, El Fiky L, Hassan O, Kotb A, El Fiky S. Anatomic Variations of the Sphenoid Sinus and Their Impact on Trans-sphenoid Pituitary Surgery. Skull Base Off J North Am Skull Base Soc Al. 2008 Jan;18(1):9-15.

21. Reittner P, Doerfler O, Goritschnig T, Tillich M, Koele W, Stammberger H, et al. Magnetic resonance imaging patterns of the development of the sphenoid sinus: a review of 800 patients. Rhinology. 2001 Sep;39(3):121-4.

22. Luginbuhl AJ, Campbell PG, Evans J, Rosen $M$. Endoscopic repair of high-flow cranial base defects using a bilayer button. The Laryngoscope. 2010 May;120(5):876-80.

23. Oldfield EH, Vortmeyer AO. Development of a histological pseudocapsule and its use as a surgical capsule in the excision of pituitary tumors. J Neurosurg. 2006 Jan;104(1):7-19.

24. Monteith SJ, Starke RM, Jane JA, Oldfield $\mathrm{EH}$. Use of the histological pseudocapsule in surgery for Cushing disease: rapid postoperative cortisol decline predicting complete tumor resection. J Neurosurg. 2012 Apr;116(4):721-7.

25. Hofstetter CP, Nanaszko MJ, Mubita LL, Tsiouris J, Anand VK, Schwartz TH. Volumetric classification of pituitary macroadenomas predicts outcome and morbidity following endoscopic endonasal transsphenoidal surgery. Pituitary. 2012 Sep;15(3):450-63.

26. Woodworth GF, Patel KS, Shin B, Burkhardt $J-K$, Tsiouris AJ, McCoul ED, et al. Surgical outcomes using a medial-to-lateral endonasal endoscopic approach to pituitary adenomas invading the cavernous sinus J Neurosurg. 2014 May;120(5):1086-94.
27. Ceylan S, Koc K, Anik I. Endoscopic endonasal transsphenoidal approach for pituitary adenomas invading the cavernous sinus. J Neurosurg. 2010 Jan;112(1):99-107.

28. Ding D, Starke RM, Sheehan JP. Treatment paradigms for pituitary adenomas: defining the roles of radiosurgery and radiation therapy. J Neurooncol. 2014 May;117(3):445-57.

29. Dallapiazza RF, Jane JA. Outcomes of Endoscopic Transsphenoidal Pituitary Surgery. Endocrinol Metab Clin North Am. 2015 Mar:44(1):105-15

30. Shakir HJ, Garson AD, Sorkin GC, Mokin M, Eller JL, Dumont TM, et al. Combined use of covered stent and flow diversion to seal iatrogenic carotid injury with vessel preservation during transsphenoidal endoscopic resection of clival tumor. Surg Neurol Int. 2014;5:81.

31. Koitschev A, Simon C, Löwenheim H, Naegele $\mathrm{T}$, Ernemann U. Management and outcome after internal carotid artery laceration during surgery of the paranasal sinuses. Acta Otolaryngol (Stockh). 2006 Jul;126(7):730-8.

\section{Key Points}

1. Understand the principles of pituitary surgery including the key-elements of surgical planning and decision-making

2. Identify the technical nuances distinguishing the endoscopic from the microscopic transsphenoidal approach

3. Understand the strategies utilized during the nasal, sphenoidal, and sellar stages of surgery that maximize tumor resection while minimizing complications and preserving sinonasal anatomy/function

\section{Corresponding Author}

\section{Christopher J. Farrell, MD}

Department of Neurological Surgery

Sidney Kimmel Medical College

Thomas Jefferson University

909 Walnut St, 2nd Floor

Philadelphia, PA 19107

E: christopher.farrell@jefferson.edu 